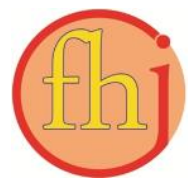

Faletehan Health Journal, 8 (3) (2021) 187-193

www. journal.Ippm-stikesfa.ac.id/ojs/index.php/FHJ

ISSN 2088-673X | e-ISSN 2597-8667

\title{
Aplikasi Fitofarmaka Akupresur Menggunakan Aromaterapi Essential Oil Lemon untuk Mengatasi Dismenore pada Remaja
}

\author{
Husnul Khotimah ${ }^{1 *}$, Sri Utami Subagio ${ }^{1}$ \\ ${ }^{1}$ Fakultas Ilmu Kesehatan, Universitas Faletehan \\ *Correspondence Author: husnulmehu@gmail.com
}

\begin{abstract}
Abstrak
Penanganan dismenore selama ini lebih banyak kepada pemberian terapi farmakologik tetapi jarang menggunakan fitofarmaka seperti akupresur dan aromaterapi. Tujuan penelitian ini adalah untuk menganalisis bagaimana aplikasi akupresur menggunakan aromaterapi essential oil lemon untuk mengatasi nyeri dismenore pada remaja. Jenis penelitian ini adalah penelitian kuantitatif berjenis quasi eksperimen dengan non-equivalent control group design. Populasi dari penelitian ini berjumlah 185 . Teknik pengambilan sampel menggunakan pendekatan non-probability sampling (sampling jenuh). Penentuan jumlah sampel dalam peneliti ini memakai perhitungan dari Sastroasmoro \& Ismael dengan jumlah sampel 52 terdiri dari 26 kelompok eksperimen dan 26 kelompok kontrol. Analisis data menggunakan Wilcoxon signed rank test untuk menguji masing-masing kelompok eksperimen dan kelompok kontrol dan Mann Whitney untuk membandingkan antara keduanya. Hasil analisis statistik menggunakan Wilcoxon signed rank test pada kelompok eksperimen $(p=0,000)$ dan kelompok kontrol $(p=0.000)$ menunjukkan penggunaan terapi essential oil lemon efektif untuk mengatasi dismenore. Hasil analisis statistik menggunakan Mann Whitney mendapatkan nilai p 0,000 lebih kecil dari tingkat signifikansi $0,05(p<0,05)$. Artinya akupresur menggunakan aromaterapi lebih efektif untuk mengurangi dismenore dibandingkan akupresur saja. Akupresur yang diberikan membuat responden rileks dan imunitas meningkat, ditambah lagi pemijatan menggunakan aromaterapi yang dihirupkan sampai pada paru memberikan manfaat baik secara psikologis dan fisik.
\end{abstract}

Kata Kunci: Akupresur, Aromaterapi, Dismenore

\section{The Application of Acupressure Phytopharmaceutical Using Lemon Essential Oil Aromatherapy to Overcome Dysmenorrhea in Adolescents}

\begin{abstract}
The treatment of dysmenorrhea mostly used pharmacological therapy but rarely applied phytopharmaceuticals such as acupressure and aromatherapy. The purpose of this study was to analyze the application of acupressure using lemon essential oil aromatherapy to treat dysmenorrhea pain in adolescents. The research type was quantitative and the research design was quasi experiment with non-equivalent control group design. The population of this study amounted to 185. The sampling technique used a non-probability sampling approach (saturated sampling). The sample size was determined by using calculations from Sastroasmoro \& Ismael with a total sample of 52 people consisting of 26 in experimental group and 26 in control group. The data analysis used Wilcoxon signed rank test to examine the experimental and control group and Mann Whitney to compare them. The results of statistical analysis using Wilcoxon signed rank test for the experimental group $(p=0.000)$ and the control group $(p=0.000)$ showed that lemon oil essential therapy was effective in overcoming dysmenorrhea. The results of statistical analysis using Mann Whitney obtained $p$ value 0.000 which is smaller than $(p<0.05)$. It can be concluded that acupressure using aromatherapy is more effective in reducing dysmenorrhea than acupressure alone. The acupressure given made the respondents relaxed and their immunity increased, and the massages using aromatherapy that is inhaled to the lungs provides benefits both psychologically and physically.
\end{abstract}

Keywords: Acupressure, Aromatherapy, Dysmenorrhea 


\section{Pendahuluan}

Menstruasi merupakan kejadian fisiologis bagi perempuan yang sudah remaja, dalam hal ini hormon-hormon reproduksi mereka sudah mulai bekerja. Menstruasi merupakan sebuah indikator kematangan seksual pada remaja putri. Akan tetapi, sayangnya tidak semua remaja dapat melalui masa menstruasi dengan biasa, karena banyak juga yang mengalami keluhan- keluhan pada saat menstruasi berlangsung (Solehati et al., 2018).

Salah satu keluhan selama menstrusasi adalah dismenore. Dismenore (nyeri haid) adalah nyeri perut yang berasal dari kram rahim yang terjadi selama haid. Dismenore terdiri dari dismenore primer dan sekunder. Sebanyak $90 \%$ dari remaja wanita di seluruh dunia mengalami masalah saat haid dan lebih dari $50 \%$ dari wanita haid mengalami dismenore primer. Dismenore primer merupakan nyeri haid yang tidak didasari kondisi patologis, sedangkan dismenore sekunder merupakan nyeri haid yang didasari dengan kondisi patologis (Larasati \& Alatas, 2016). Penanganan dismenore selama ini lebih banyak kepada pemberian terapi farmakologik, seperti pemberian analgesik. Obat analgesik dapat menimbulkan efek toleransi, ketergantungan dan gejala putus obat. Cara penyembuhan lain untuk mengurangai gejala dismenore selain terapi farmakologik adalah dengan pemberian akrupresur dan aromaterapi (Batubara, 2016)

Akupresur adalah pengobatan cina yang sudah dikenal sejak ribuan tahun lalu dan dengan memberikan tekanan atau pemijatan dan menstimulasi titik-titik tertentu dalam tubuh. Tujuannya untuk merangsang kemampuan alami menyembuhkan diri sendiri dengan cara mengembalikan keseimbangan energi positif tubuh (Fengge, 2012).

Penatalaksanaan dalam menurunkan nyeri menstruasi dengan relaksasi yaitu menggunakan aromaterapi lemon. Aromaterapi lemon untuk meningkatkan mood dan mengurangi rasa marah. Minyak aromaterapi lemon mempunyai kandungan limeone 66-80, geranil asetat, netrol, terpine $6-14 \%, \alpha$ pinene $1-4 \%$ dan mrcyne. Limeone adalah komponen utama dalam senyawa kimia jeruk yang dapat menghambat sistem kerja prostaglandin sehingga dapat mengurangi nyeri (Rompas \& Gannika, 2019).
Banyak penelitian yang mengkaji tentang pengurangan nyeri Dismenore dengan menggunakan akupresur dan aromaterapi. Diantaranya adalah penelitian yang dilakukan oleh Fitria tahun 2020 mengkaji tentang Pengaruh Akupresur dengan Teknik Tuina terhadap nyeri haid (dismenorhea), penelitian Pangastuti tahun 2019 membahas tentang Pengaruh Akupresur pada titik tai chong dan guanyuan terhadap nyeri haid (dismenorhea). Begitu pula ada beberapa penelitian yang hanya membahas tentang aromaterapi terhadap Dimenore diantaranya adalah Rompas tahun 2019 menggali tentang Pengaruh aromaterapi lemon (citrus) terhadap nyeri haid (dismenorhea). Penelitian lainnya juga ada yang membahas tentang pemberian massage menggunakan aromaterapi tetapi tidak membandingkan keduanya, yaitu Nursangadah tahun 2019 yang membahas tentang Pengaruh Pemberian Masase Effleurage Menggunakan Minyak Aromaterapi Mawar terhadap nyeri haid (dismenorhea) (Fitria \& Haqqattiba'ah, 2020; Nursangadah, 2019; Pangastuti \& Mukhoirotin, 2019; Rompas \& Gannika, 2019). Akan tetapi masih jarang peneliti yang menggabungkan 2 terapi ini untuk mengatasi nyeri Dismenore. Oleh karena itu peneliti tertarik untuk menganalisis bagaimana efektifitas akupresur dengan aromaterapi untuk mengatasi nyeri Dismenore. Oleh karena itu peneliti tertarik untuk menganalisis tentang efektivitas akupresur dengan pemberian aromaterapi terhadap penurunan tingkat nyeri Dismenore pada mahasiswa tingkat I Program Studi DIII kebidanan Universitas Faletehan tahun 2021.

\section{Metodologi Penelitian}

Jenis penelitian ini adalah penelitian kuantitatif, dengan rancangan penelitian Quasi Experimental Design dengan Nonequivalent Control Group Design yaitu dimana peneliti dapat mengontrol semua variabel luar yang mempengaruhi jalannya eksperimen. Dalam design ini, terdapat kelompok kontrol dan kelompok eksperimen dimana baik kelompok kontrol maupun kelompok eksperimen diberikan pre test, kemudian diberikan perlakuan dan terakhir diberikan post test. Penelitian ini dilakukan pada mahasiswa Program Studi D III Kebidanan Fakultas Ilmu Kesehatan Universitas Faletehan Kabupaten Serang Provinsi 
Faletehan Health Journal, 8 (3) (2021) 187-193

www. journal.Ippm-stikesfa.ac.id/ojs/index.php/FHJ

Banten. Penelitian ini dilaksanakan pada Agustus September 2021.

Populasi dari penelitian ini adalah seluruh mahasiswa prodi D3 Kebidanan yang berjumlah 185. Teknik pengambilan sampel menggunakan pendekatan non probability sampling (sampling jenuh). Penentuan jumlah besar sampel dalam peneliti ini memakai perhitungan dengan menggunakan rumus besar sampel menurut Sastroasmoro \& Ismael (2010). Berdasarkan rumus tersebut maka didapatkan jumlah sampel sebanyak sebanyak 26 orang pada masing-masing kelompok. Sehingga jumlah responden sebanyak 52 orang, 26 orang sebagai kelompok eksperimen dan 26 orang kelompok kontrol. Sampel yang diambil adalah yang telah memenuhi kriteria inklusi: mahasiswi yang bersedia menjadi responden, mahasiswa yang sedang menstruasi, skala nyeri menstruasi 4 sampai 6 sedang, mahasiswi yang masih aktif kuliah di Program Studi DIII Kebidanan Fakultas Ilmu Kesehatan Universitas Faletehan, tidak menggunakan terapi/pengobatan yang lain.

Data yang mendukung dalam penelitian ini yaitu data primer melalui intervensi langsung kepada responden. Pengukuran intensitas nyeri dilakukan dengan menggunakan numerik Visual Analog Scale (VAS). Peneliti memasukkan skala intensitas nyeri dengan rentang skala nyeri 0-10 : $0=$ Tidak nyeri, $1-3=$ Nyeri ringan, $4-6=$ Nyeri sedang, 7-9 = Nyeri berat, $10=$ Tak tertahankan. Sebelum intervensi, diberikan Pre test berupa penilaian skala rasa nyeri Dismenore. Kemudian peneliti melakukan intervensi pada kelompok perlakuan dengan cara melakukan terapi akupresur menggunakan aromaterapi essential oil lemon $10 \mathrm{ml}$ pada titik LI 11 (terletak di lipatan siku), LI 4 (terletak di bagian lunak antara jari telunjuk dan ibu jari) dan ST 36 (terletak pada 3 jari di bawah lutut sebelah kanan tulang kering) pada hari 1-2 haid selama 30 menit, sedangkan pada kelompok kontrol diberikan perlakuan berupa terapi akupresur tanpa menggunakan aromaterapi pada titik LI 11, LI 4, dan ST 36 pada hari 1-2 haid selama 30 menit. Setelah itu dilakukan post tes untuk mengukur skala nyeri Dismenore apakah ada perbedaan atau tidak.

Akupresur dilakukan oleh 2 orang peneliti (ketua dan anggota) dan dibantu oleh 2 orang enumerator. Jadi yang mengumpulkan data berjumlah 4 orang. Instrument yang digunakan adalah Aromaterapi essential oil lemon $10 \mathrm{ml}$, daftar tilik akupresur dan kuesioner pengukuran nyeri Dismenore. Analisis data menggunakan Wilcoxon Signed Rank Test untuk menguji masingmasing kelompok eksperimen dan kelompok kontrol, dan Mann Whitney untuk membandingkan antara keduanya. Penelitian ini telah memperoleh izin etik dari Komisi Etik Penelitian Kesehatan Universitas Muhammadiyah Prof. DR HAMKA dengan nomor izin etik 03/21.06/01074. Penelitian ini didanai oleh Direktorat Riset dan Pengabdian Masyarakat Kementerian Riset dan Teknologi / Badan Riset dan Inovasi Nasional dengan nomor kontrak penelitian 065/SP2H/LT/DRPM//2021.

\section{Hasil dan Pembahasan}

Tabel 1. Distribusi Frekuensi Berdasarkan Data Identitas Responden Dismenore $(\mathrm{n}=54)$

\begin{tabular}{lcc}
\hline \multicolumn{1}{c}{ Karakteristik } & n & \% \\
\hline Menarche & & \\
\hline 11 tahun & 19 & 36,5 \\
\hline 12 tahun & 17 & 32,7 \\
\hline 13 tahun & 16 & 30,8 \\
\hline Nyeri Dismenore & & \\
\hline Kadang-kadang & 4 & 7,7 \\
\hline Sering & 48 & 92,3 \\
\hline
\end{tabular}

Berdasarkan tabel 1 di atas menunjukkan hampir setengahnya responden mengalami menarche pada usia 11 tahun $(36,5 \%)$ dan hampir seluruhnya $(92,3 \%)$ responden sering mengalami Dismenore.

Tabel 2. Analisis Data Dismenore pada Kelompok Intervensi $(\mathrm{n}=26)$

\begin{tabular}{cccccc}
\hline Post Test-Pre Test & N & Mean Rank & Sum of Ranks & Nilai Z & P Value \\
\hline Negative Ranks & 26 & 13,5 & 351 & $-4,505$ & 0,000 \\
Positif Ranks & 0 & 0 & 0 & & \\
\hline
\end{tabular}

Tabel 3. Analisis Data Dismenore pada Kelompok Kontrol $(\mathrm{n}=26)$

\begin{tabular}{cccccc}
\hline Post Test - Pre Test & N & Mean Rank & Sum of Ranks & Nilai Z & P Value \\
\hline Negative Ranks & 25 & 13 & 325 & $-4,428$ & 0,000 \\
Positif Ranks & 0 & 0 & 0 & & \\
Ties & 1 & & & & \\
\hline
\end{tabular}


Tabel 4. Analisis Perbandingan antara Kelompok Intervensi dan Kelompok Kontrol ( $\mathrm{n}=52$ )

\begin{tabular}{cccccc}
\hline Variabel & N & Mean Rank & Sum of Ranks & Nilai $\boldsymbol{Z}$ & P Value \\
\hline Post Test Kontrol & 26 & 37,08 & 964 & $-5,103$ & 0,000 \\
Post Test Eksperimen & 26 & 15,92 & 414 & & \\
\hline
\end{tabular}

Pada tabel 2 menunjukkan bahwa negative Ranks (selisih negatif) sebesar 26, artinya terdapat penurunan Dismenore sebesar 26 dari nilai pretest ke nilai post test dengan rata-rata penurunan sebesar 13,5 sedangkan jumlah rangking negatif sebesar 351. Positif Ranks (selisih positif) sebesar 0 menunjukkan bahwa tidak ada responden yang mengalami peningkatan nyeri Dismenore dari nilai pre test ke nilai post test.

Berdasarkan hasil analisis statistik menggunakan Wilcoxon Sign Ranks diketahui nilai p 0.000 lebih kecil dari $(<0.05)$ maka dapat disimpulkan bahwa terdapat perbedaan skala Dismenore antara pre test dan post test pada kelompok intervensi sehingga dapat disimpulkan bahwa terdapat pengaruh akupresur menggunakan aromaterapi terhadap Dismenore pada mahasiswi DIII Kebidanan Universitas Faletehan.

Pada tabel 3 menunjukkan bahwa negative Ranks (selisih negatif) sebesar 25, artinya terdapat penurunan Dismenore dari nilai pretest ke nilai posttest dengan rata-rata penurunan sebesar 13 sedangkan jumlah rangking negatif sebesar 325 . Positif Ranks (selisih positif) bernilai 0 menunjukkan bahwa tidak ada responden yang mengalami peningkatan nyeri Dismenore. Ties sebesar 1 menunjukkan ada 1 nilai yang sama antara pretest dan posttest.

Berdasarkan hasil analisis statistik menggunakan Wilcoxon Sign Ranks diketahui nilai p 0.000 lebih kecil dari $(<0.05)$ dapat disimpulkan bahwa terdapat perbedaan skala Dismenore antara pretest dan post test pada kelompok kontrol sehingga dapat disimpulkan bahwa terdapat pengaruh akupresur tanpa menggunakan aromaterapi terhadap Dismenore pada mahasiswi DIII Kebidanan Universitas Faletehan.

Berdasarkan hasil analisis statistik menggunakan Mann Whitney diketahui nilai $\mathrm{p}$ 0.000 lebih kecil dari $(<0.05)$ dapat disimpulkan bahwa Hipotesis diterima. Dengan demikian dapat dikatakan bahwa ada perbedaan skala nyeri Dismenore sehingga dapat disimpulkan bahwa ada pengaruh akupresur menggunakan aromaterapi terhadap Dismenore pada mahasiswi DIII Kebidanan Universitas Faletehan.
Berdasarkan hasil penelitian, fitofarmaka yang efektif dalam mengurangi nyeri Dismenore terbagi menjadi 3 jenis, yaitu 1) Pemberian akupresur, 2) Pemberian aromaterapi, 3) Pemberian akupresur mengunakan aromaterapi. Berikut penjelasannya:

\section{Pemberian Akupresur}

Akupresur adalah pengobatan cina yang sudah dikenal sejak ribuan tahun lalu dan dengan memberikan tekanan atau pemijatan dan menstimulasi titik-titik tertentu dalam tubuh (Fengge, 2012). Pada dasarnya terapi akupresur merupakan pengembangan dari teknik akupuntur, tetapi media yang digunakan bukan jarum, tetapi jari tangan atau benda tumpul. Tujuannya untuk merangsang kemampuan alami menyembuhkan diri sendiri dengan cara mengembalikan keseimbangan energi positif tubuh (Fengge, 2012).

Titik-titik meridian (accupoint) terletak di seluruh tubuh, dekat dengan permukaan kulit dan terhubung satu sama lain melalui jaringan yang komplek dari meridian. Setiap accupoint mempunyai efek khusus pada sistem tubuh, atau organ tertentu. Menstimulasi dan memijat secara lembut titik tersebut akan terjadi perubahan fisiologi tubuh dan akan mempengaruhi keadaan mental dan emosional (Panggabean, 2019).

Salah satu efek penekanan titik akupresure dapat meningkatkan kadar endorfin yang berguna sebagai pereda nyeri yang diproduksi tubuh dalam darah dan opioid peptida endogeneus di dalam susunan syaraf pusat. Jaringan syaraf akan memberi stimulus pada sistem endokrin untuk melepaskan endorfin sesuai kebutuhan tubuh dan diharapkan dapat menurunkan rasa nyeri saat menstruasi. Akupresur dapat dilakukan dengan penekanan pada satu titik (tunggal) maupun gabungan atau kombinasi yang terbukti dapat digunakan untuk menangani dismenore (Hasanah, 2014; Widyaningrum, 2013).

Akupresur ini mudah dipelajari dan juga membutuhkan waktu yang sedikit untuk menerapkannya. Menurut konsep dalam akupresur bahwa seseorang mengalami gangguan fungsi tubuh bila terjadi ketidakseimbangan dalam 
Faletehan Health Journal, 8 (3) (2021) 187-193

www. journal.Ippm-stikesfa.ac.id/ojs/index.php/FHJ

ISSN 2088-673X | 2597-8667

tubuhnya. Untuk mengembalikan kondisi tak seimbang itulah sejumlah titik meridian tertentu sesuai dengan gangguannya, perlu dipicu dengan cara ditekan. Acupoint terletak di seluruh tubuh, dekat dengan permukaan kulit dan terhubung satu sama lain melalui jaringan yang komplek dari meridian (Panggabean, 2019).

Penelitian yang dilakukan oleh Fitria tahun 2020 mengkaji tentang Pengaruh Akupresur dengan Teknik Tuina terhadap nyeri haid (dismenorhea) (Fitria \& Haqqattiba'ah, 2020). Demikian pula penelitian oleh Pangastuti tahun 2019 membahas tentang Pengaruh Akupresur pada titik tai chong dan guanyuan terhadap nyeri haid (dismenorhea) (Pangastuti \& Mukhoirotin, 2019). Menurut Yu Zen Wang, titik LI4 digunakan dalam masalah sirkulasi darah dan menghentikan energi. Qi dalam bahasa akupresur adalah energi. Skema pengobatan akupunktur semi standar diterapkan, Hal ini sejalan dengan penelitian ini bahwa responden yang diberikan akupresur salah satunya titik LI4 ternyata pada saat post test nyerinya sedang sampai tidak nyeri sampai nyeri ringan (Wang et al., 2013).

Penelitian lainya yang sejalan dengan penelitian ini adalah penelitian yang dilakukan oleh Prihatin tahun 2019 yang menemukan bahwa ada perbedaan antara nilai pre dan nilai post. Ini menunjukkan bahwa ada pengaruh massage effleurage terhadap penurunan intensitas nyeri remaja putri SMAN 2 Kota Ternate, identifikasi remaja yang mengalami dismenore dapat dilakukan secara rutin sehingga dapat mengantisipasi kemungkinan atau faktor risiko yang dapat terjadi (Prihatin, 2019). Begitu pula penelitian oleh Zuraida tahun 2020 sejalan dengan penelitian ini, menyebutkan bahwa ada pengaruh massage effeleurage terhadap penurunan nyeri haid dimana terjadi penurunan rata-rata tingkat nyeri haid setelah pemberian massage effleurage secara uji statistik didapatkan $\mathrm{p}$ Value $=0,005$ $(\mathrm{p}<0,05)$. Peneliti menyarankan kepada remaja putri, khususnya remaja putri di SMA N 1 Sutera Kabupaten Pesisir Selatan untuk dapat menggunakan terapi Massage Effleurage ini dalam penanganan nyeri haid/dismenore karena lebih mudah, efisien dan dapat dilakukan secara mandiri (Zuraida \& Aslim, 2020). Massage effleurage adalah salah satu bentuk massage menggunakan telapak tangan, namun sedikit berbeda dengan akupresur dimana pemijatan hanya pada 1 titik tetapi masih sama2 metode mengurangi dismenore.

\section{Pemberian Aromaterapi}

Aromaterapi merupakan suatu bentuk pengobatan alternatif menggunakan bahan tanaman volatil, banyak dikenal dalam bentuk minyak esensial dan berbagai macam bentuk lain yang bertujuan untuk mengatur fungsi kognitif, mood, dan kesehatan. Aromaterapi dibentuk dari berbagai jenis ekstrak tanaman seperti bunga, daun, kayu, akar tanaman, kulit kayu, dan bagian-bagian lain dari tanaman dengan cara pembuatan yang berbeda-beda dengan cara penggunaan dan fungsinya masing-masing. Ada banyak jenis aromaterapi, seperti minyak esensial, dupa, lilin, garam, minyak pijat, dan sabun. Terdapat 12 Jenis tanaman yang digunakan sebagai esktrak juga sangat banyak, yaitu rosemary, sandalwood, jasmine, orange, basil, ginger, lemon, tea tree, ylang-ylang, dan masih banyak lagi (Dewi \& Purwoko, 2016). Rompas dan Gannika dalam penelitiannya menyebutkan bahwa ada pengaruh aromaterapi lemon (Citrus) terhadap Penurunan nyeri menstruasi pada mahasiswi Ilmu Keperawatan Fakultas Kedokteran Universitas Sam Ratulangi Manado (Rompas \& Gannika, 2019).

Ji-Ah Song (2018) juga menyatakan bahwa aromaterapi dapat menurunkan dismenore. Ji-Ah Song menyatakan bahwa antara kelompok eksperimen yang mendapat intervensi aromaterapi, dan kelompok kontrol yang tidak mendapat perlakuan apapun menunjukkan perbedaan yang signifikan secara statistik $(Z=7,79, p<.001$, Higgins $\mathrm{I} 2=0 \%$ ). Dibandingkan dengan kelompok plasebo, yang menerima pengobatan minyak plasebo, skor dismenore pada kelompok eksperimen menurun 1,71 poin (berbeda rata-rata, 1,71), menunjukkan perbedaan yang signifikan secara statistik $(Z=4,51$, $\mathrm{p}<.001$ ), tetapi tinggi heterogenitas (Higgins $\mathrm{I} 2=81 \%$ ) (Song et al., 2018).

Hasil penelitian di India yang dilakukan pada tahun 2014, lemon menjadi salah satu tanaman yang digunakan sebagai pengobatan untuk mengobati nyeri dismenore. Tanaman yang digunakan untuk pengobatan gangguan menstruasi yang berbeda didokumentasikan dan dianalisis untuk masalah etnoginekologi. Studi ini mengungkapkan beberapa tanaman seperti Triticum aestivum, Rubiamanjith, Dalbergia sissoo, Raphanus sativus, Citrus limon, Allium cepa, Trigonella foenum-graecum, Elettaria ardamomum dll sangat penting untuk gangguan menstruasi. Studi farmakologi lebih lanjut dari 
tanaman ini dapat memberikan beberapa obat penting untuk pengobatan gangguan menstruasi yang umum (Bhatia et al., 2015).

\section{Pemberian Akupresur menggunakan Aromaterapi}

Apay juga mengatakan bahwa skor yang lebih tinggi mencerminkan tingkat keparahan dismenore yang lebih besar. Empat puluh empat siswa mengajukan diri untuk berpartisipasi dalam penelitian ini. Ketika pijat lavender dan pijat plasebo dibandingkan, skor skala analog visual dari pijat lavender ditemukan menurun pada tingkat yang signifikan secara statistik. Penelitian ini menunjukkan bahwa pijat efektif dalam mengurangi dismenore. Selain itu, penelitian ini menunjukkan bahwa efek pijat aromaterapi terhadap nyeri lebih tinggi daripada pijat placebo (Apay et al., 2012).

Pijat aromaterapi dengan minyak atsiri merupakan metode komplementer yang efektif untuk meredakan nyeri pada dismenore primer. Pijat aromaterapi dengan minyak esensial lebih unggul daripada pijat dengan minyak plasebo. Pijat aromaterapi hanya dengan minyak lavender memiliki ukuran efek yang lebih tinggi daripada pijat dengan lavender plus minyak esensial campuran. Pijat aromaterapi dapat digunakan sebagai metode nonfarmakologis untuk mengurangi nyeri dismenore primer (Sajjadi et al., 2018).

\section{Simpulan}

Metode akupresur menggunakan aromaterapi (kelompok intervensi) dan metode akupresur tanpa menggunakan aromaterapi (kelompok kontrol) sama-sama berpengaruh terhadap penurunan skala nyeri Dismenore. Metode akupresur menggunakan aromaterapi lebih memberikan dampak yang positif terhadap penurunan skala nyeri Dismenore bila dibandingkan dengan metode akupresur tanpa menggunakan aromaterapi.

\section{Referensi}

Apay, S. E., Arslan, S., Akpinar, R. B., \& Celebioglu, A. (2012). Effect of aromatherapy massage on dysmenorrhea in Turkish students. Pain Management Nursing, 13(4), 236-240.

Batubara, J. R. L. (2016). Adolescent development (perkembangan remaja). Sari Pediatri, 12(1), 21-29.
Bhatia, H., Sharma, Y. P., Manhas, R. K., \& Kumar, K. (2015). Traditional phytoremedies for the treatment of menstrual disorders in district Udhampur, J\&K, India. Journal of Ethnopharmacology, 160, 202-210.

Dewi, C. Y. P., \& Purwoko, Y. (2016). Pengaruh aromaterapi rosemary terhadap atensi. Diponegoro University.

Fengge, A. (2012). Terapi akupresur manfaat dan teknik pengobatan. Yogyakarta: Crop Circle Corp.

Fitria, F., \& Haqqattiba'ah, A. (2020). Pengaruh Akupresur dengan Teknik Tuina terhadap Pengurangan Nyeri Haid (Disminore) pada Remaja Putri. Jurnal Ners Dan Kebidanan (Journal of Ners and Midwifery), 7(1), 73-81.

Hasanah, O. (2014). Efektifitas Akupresur terhadap Dismenore pada Remaja Putri. Riau University.

Larasati, T. A., \& Alatas, F. (2016). Dismenore primer dan faktor risiko Dismenore primer pada Remaja. Jurnal Majority, 5(3), 79-84.

Nursangadah, S. (2019). Aplikasi Massage Effleurage Menggunakan Minyak Aromaterapi Mawar Untuk Mengatasi Nyeri Akut Pada Remaja dengan Dismenore. Skripsi, Universitas Muhammadiyah Magelang.

Pangastuti, D., \& Mukhoirotin, M. (2019). Pengaruh Akupresur Pada Titik Tai Chong Dan Guanyuan Terhadap Penurunan Intensitas Nyeri Haid (Dismenorhea) Pada Remaja Putri. Jurnal EDUNursing, 2(2), 5462.

Panggabean, N. S. H. (2019). Pengaruh Akupresur Terhadap Dismenore pada Remaja di SMP Swasta Islam Terpadu Siti Hajar Medan.

Prihatin, S. (2019). Pengaruh massage effleurage terhadap penurunan intensitas nyeri dismenorea primer pada remaja putri di SMAN 2 Kota Ternate tahun 2018. Medica majapahit (Jurnal Ilmiah Kesehatan Sekolah Tinggi Ilmu Kesehatan Majapahit), 11(2), 18.

Rompas, S., \& Gannika, L. (2019). Pengaruh aromaterapi lemon (citrus) terhadap penurunan nyeri menstruasi pada mahasiswi Program Studi Ilmu Keperawatan Fakultas Kedokteran Universitas Sam Ratulangi Manado. Jurnal keperawatan, 7(1).

Sajjadi, M., Bahri, N., \& Abavisani, M. (2018). Aromatherapy massage with geranium 
Faletehan Health Journal, 8 (3) (2021) 187-193

essence for pain reduction of primary dysmenorrhea: a double blind clinical trial. The Iranian Journal of Obstetrics, Gynecology and Infertility, 20(12), 50-57.

Solehati, T., Trisyani, M., \& Kosasih, C. E. (2018). Gambaran pengetahuan, sikap, dan keluhan tentang menstruasi diantara remaja puteri.

Jurnal Keperawatan Komprehensif (Comprehensive Nursing Journal), 4(2), 8691.

Song, J.-A., Lee, M., Min, E., Kim, M.-E., Fike, G., \& Hur, M.-H. (2018). Effects of aromatherapy on dysmenorrhea: A systematic review and meta-analysis. International Journal of Nursing Studies, 84, 1-11.

Wang, Y.-J., Hsu, C.-C., Yeh, M.-L., \& Lin, J.-G. (2013). Auricular acupressure to improve menstrual pain and menstrual distress and heart rate variability for primary dysmenorrhea in youth with stress. EvidenceBased Complementary and Alternative Medicine, 2013.

Widyaningrum, H. (2013). Pijat refleksi \& 6 terapi alternatif lainya. Media Pressindo.

Zuraida, Z., \& Aslim, M. (2020). Pengaruh Massage Effleurage Terhadap Penurunan Nyeri Dismenore Primer Pada Remaja Putri di SMAN 1 Sutera Kabupaten Pesisir Selatan. Menara Ilmu, 14(1). 